\title{
Fulminant Hepatitis: Definitions, Causes and Management
}

\author{
Vincenzo Morabito ${ }^{*}$, Danielle Adebayo ${ }^{2}$ \\ ${ }^{1}$ Department of “P. Stefanini”, General Surgery and Organ Transplant, Sapienza University of Rome, Rome, Italy \\ ${ }^{2}$ Liver Failure Group, UCL Institute for Liver and Digestive Health, UCL Medical School, Royal Free Hospital, \\ London, UK \\ Email: vemorabito@gmail.com
}

Received 28 February 2014; revised 5 April 2014; accepted 13 April 2014

Copyright (C) 2014 by authors and Scientific Research Publishing Inc.

This work is licensed under the Creative Commons Attribution International License (CC BY). http://creativecommons.org/licenses/by/4.0/

(c) (i) Open Access

\begin{abstract}
Fulminant hepatitis (FH) is a rare and devastating syndrome caused by a variety of hepatic insults. It characterized by severe metabolic derangements, neurologic complications and ultimately, multiorgan failure. Liver transplantation is the gold standard therapy for patients with irreversible FH. The major areas of current research in this field include the development of: hepatic support devices, strategies to accelerate hepatic regeneration and criteria for accurate prognostic classification of patients. This review aims to focus on the definitions, aetiologies and management strategies for FH.
\end{abstract}

\section{Keywords}

Fulminant Hepatitis, Liver Transplant, Liver Support, Intensive Care

\section{Introduction}

Fulminant hepatitis (FH) is a rare but devastating disease, often affecting young individuals, despite recent therapeutic advances, is associated with significant morbidity and mortality [1]. Prior to transplantation, most series suggested a less than $15 \%$ survival in patients with FH. Currently, the overall short-term survival (one year) including those undergoing transplantation is greater than 65\% [2]. Due to its rarity, FH has been difficult to study in depth and therefore, very few controlled therapy trials have been performed.

The pathogenesis of acute liver failure (ALF) includes both direct and immune-mediated liver injury triggered by diverse aetiologies. Innate immune-mediated injury is initiated early and may then be followed by injury resulting from adaptive immune responses. Innate immune activation is aetiology-specific. Pathogen-associated

\footnotetext{
*Corresponding author.
} 
molecular patterns (PAMPs) are more important in ALF caused by hepatotropic viruses, whereas damage-associated molecular patterns (DAMPs), which are endogenous signals derived from injured cells, are more important in toxic aetiologies [3]. Many cell types participate in the innate immune response, including monocytes, macrophages, dendritic cells, leukocytes and natural killer cells. These cells express receptors that can recognize both PAMPs and DAMPs. Monocytes, macrophages, and leukocytes also constitute the effector cells of innate immunity and regulate the inflammatory response by producing reactive oxygen radicals and pro- and anti-inflammatory cytokines.

The two most common causes of death in patients with ALF are cerebral oedema and multi-organ system failure. These events are precipitated by the systemic inflammatory response syndrome (SIRS), which is mediated by release of pro-inflammatory cytokines such as: tumour necrosis factor- $\alpha$, interleukin (IL)- $1 \beta$, and IL-6 [4]. These SIRS mediators contribute to cerebral oedema by decreasing cerebrovascular tone thus, causing cerebral hyper-perfusion. Although a compensatory anti-inflammatory response syndrome mediated by anti-inflammatory cytokines (IL-4, IL-10, transforming growth factor- $\beta$ ) exists concomitantly in patients with ALF to dampen the SIRS, this persistent compensatory anti-inflammatory response syndrome may not be beneficial as it can lead to sepsis and late mortality. ALF is therefore the clinical syndrome that results from pro- and anti-inflammatory cytokines spilling into the systemic circulation from the liver. The accumulation of pro-inflammatory substances in hepatic failure results in neurological abnormalities, aggravation of injury to the liver/other organs, suppression of the ability of residual hepatocytes to perform organ-specific functions (sick cell syndrome), and inhibition of the hepatic regenerative response [5].

\section{Definitions}

In 1970, Trey and Davidson [6] proposed the well-known diagnostic criteria for fulminant hepatic failure. They defined the condition as a clinical syndrome characterized by massive liver necrosis associated with severe impairment of hepatic function, manifesting as progressive jaundice, hepatic coma, and liver atrophy developing with in 8 weeks of the onset of the first symptoms of the disease in individuals with no previous history of hepatic disease.

In 1993, O’Grady et al. [7] re-defined the syndrome as "acute liver failure" prefixed with "hyper" and "sub" to describe 2 cohorts at opposite ends of the clinical spectrum, based on the observation of a large series of patients treated at King's College Hospital, London, between 1972 and 1985. Criticisms were raised regarding the nomenclature and definition of "acute liver failure" proposed by the King' College Hospital group, especially in France [8] and India [9] as it was felt that the sub-classification was unlikely to influence management decision. In our opinion, we find the definition proposed by O'Grady et al. [7] the most useful as longer latency affects mortality.

The Practice Guideline Committee of the American Association for the Study of Liver Diseases(AASLD) [10] defines acute liver failure as "liver disease characterized by the development of hepatic encephalopathy and coagulation abnormalities, usually an international normalized ratio (INR) of $\geq 1.5$ or more, in patients without pre-existing cirrhosis, and an illness of $<26$ weeks duration”.

In this position paper, subgroups classified according to the interval between the onset of hepaticencephalopathy and the first onset of the disease symptoms; namely, the hyper-acute, acute, and sub-acute types, was shown to be unhelpful in predicting the outcomes of the patients [10]. Table 1 summarises the different proposed definitions of $\mathrm{FH}$.

\section{Causes}

The most frequent causes of acute liver failure worldwide include viral hepatitis [particularly hepatitis A virus (HAV) and hepatitis B virus (HBV)], medication overdose (in particular paracetamol), idiosyncratic drug reactions, ingestion of toxins, and metabolic disorders [11]. However, in a significant proportion of patients, the cause of the fulminant hepatitis cannot be established despite systematic screening to detect rare viruses and other less common causes which include: Wilson's disease, ischemic hepatitis, Budd-Chiari syndrome, Reye's syndrome and malignancy. In addition, some rare cases of fulminant hepatitis related to hepatitis $C$ virus infection have been described in the literature [12].

According to the European Liver Transplantation Registry, the most common causes of transplanted FH between 1972 and 2007 were viral causes (HAV: 1\%; HBV: 15\%), paracetamol overdose (8\%), non-paracetamol 
Table 1. Definitions and classifications of fulminant hepatitis.

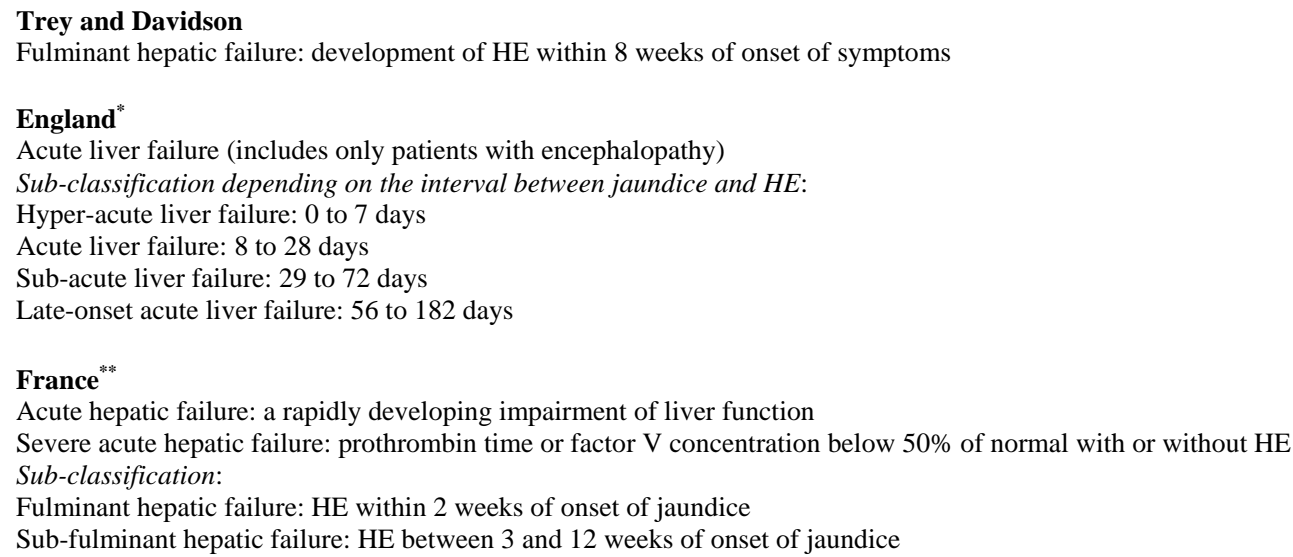

Note: HE—hepatic encephalopathy. "O’Grady JG, Schalm SW, Williams R: Acute liver failure: redefining the syndromes. Lancet 1993, 342:273-5. ${ }^{* *}$ Bernuau J, Rueff B, Benhamou JP: Fulminant and subfulminant liver failure: definitions and causes. Semin Liver Dis 1986, 6:97-106. ${ }^{* * *} \mathrm{M}$. Lee, A.M. Larson, and R. Todd Stravitz: Position Paper. The Management of Acute Liver Failure: Update 2011, Hepatology, September 2011.

drug overdose (11\%), indeterminate causes (48\%), and other causes (17\%). (European Liver Transplant Registry. Available at: http://www.ELTR.org. Accessed June 2008). In addition, ingestion of the Amanita Falloides mushroom is a relatively common cause of acute liver failure in Mediterranean countries [13].

In another survey carried out in the United states between 1998 and 2008, the major aetiologies of ALF in 1147 patients were paracetamol overdose (46\%) followed by indeterminate causes (14\%), drug-related ALF (11\%), HBV (7\%), other causes (7\%), autoimmune hepatitis (AIH; 5\%), ischemic hepatitis (4\%), HAV (3\%), and Wilson's disease (2\%) [14].

It is important to highlight that the leading aetiologies for fulminant hepatitis has changed over the years in Europe and the United states. In particular, hepatitis viruses, which were the leading cause between 1995-1996, have fallen behind drugs, in particular paracetamol, which is now the leading cause of this disease [2].

Identifying the cause of FH is imperative as it allows for early-targeted treatment to be initiated. In addition, it allows prognosis to be determined. It is well-described in the literature that the outcome of FH is significantly influenced by disease aetiology [15]. Brandsaeter et al. [16], studied 315 patients from 1990 to 2001 listed for transplantation. They found that spontaneous survival was highest in patients with HAV infection (43\%, 3/7 patients); this was followed by paracetamol overdose $(31 \%, 16 / 52)$ and HBV infection $(8 \%, 2 / 25)$. This good prognosis without liver transplantation in patients with paracetamol overdose and HAV infection has also been demonstrated in America [14]. In contrast, in this same series, patients with an indeterminate cause or nonparacetamol drug-related ALF, HBV infection, autoimmune hepatitis, Wilson's disease, or Budd-Chiari syndrome had a short-term transplant free survival of $<25 \%$ [2]. The causes of FH are summarised below (Table 2).

\section{Management}

Although patients with ALF represent a heterogeneous group, they have consistent clinical features: acute loss of hepatocellular function, the systemic inflammatory response, and multi-organ system failure [10]. To date, no single therapy has been shown to improve outcome in all ALF patients. The main aim of management is therefore supportive and dealing with any complications that may present.

Patients with FH should be managed in an intensive care unit and transferred as soon as possible to centres with a liver transplant program. 
Table 2. Causes of fulminant hepatitis.

Viral

Toxic dose-dependent

Metabolic

Vascular

Miscellanous
Hepatitis A, B, C, D, E, CMV HSV, EBV

Acetaminophen (paracetamol), Isoniazid, Tetracycline, Methotrexat, Carbon tetrachloride, Amphetamins, Amanita phalloides-Toxin

M. Wilson, alpha-1-AT-deficiency, Galactosemia, Tyrosinemia, Reye-Syndrome

Budd-Chiari-Syndrome, veno-occlusive disease, shock, heart failure

Autoimmune-hepatitis

Associated with pregnancy

HELLP Syndrome

Note. The bold font indicate the main causes of fulminant hepatitis. CMV: Cytomegalovirus; HSV: Herpes Simplex Virus; EBV Epstein-Barr Virus.

As most patients with acute liver failure develop dome degree of circulatory dysfunction, attention must be paid to fluid management and haemodynamics. In addition, surveillance for, and prompt treatment of infection is also crucial. Coagulation parameters, complete blood counts, metabolic panels (including glucose) and arterial blood gas should be checked frequently. Serum aminotransferases and bilirubin are generally measured daily to follow the course of the condition; however, changes in aminotransferase levels correlate poorly with prognosis, and a decline should not be interpreted as a sign of improvement [10].

\subsection{Intensive Care}

The survival of patients with acute liver failure has improved over time because of early disease recognition and better intensive care management. Despite this, mortality remains high without liver transplantation and exceeds $80 \%$ in the most severe cases. Patient outcome is often determined by the severity and number of organ failure [17].

Cerebral oedema represents an important cause of death in patients with ALF. Although its incidence may be declining, up to $25 \%$ of patients are still succumbing to the sequelae of intra-cerebral hypertension [17]. Patients with progressive encephalopathy, grade III or IV, require intubation and sedation as high-grade encephalopathy usually occurs as a consequence of cerebraledema. The pathogenesis of cerebral oedema in patients with ALF appears to be multifactorial. Prolonged time periods of cerebral perfusion pressure (CPP) $<50 \mathrm{mmHg}$ or an intra-cranial pressure (ICP) of $>40 \mathrm{mmHg}$ are associated with a poor neurological outcome [18]. CPP below 40 mmHg for more than 2 hours was considered a contraindication for liver transplantation; however, a case series of four patients with refractory ICP elevation above $35 \mathrm{mmHg}$ and CPP below $50 \mathrm{mmHg}$ who made a full neurological recovery contradicted previous findings [19].

Close monitoring of ICP is pivotal through invasive or non-invasive methods in ALF. Although intra-cranial bolt insertion gives a more direct measurement of cerebral status, it carries a risk of intracranial haemorrhage. In a recent observational study, the use and complication rate of ICP monitoring via bolt insertion was prospectively studied in 92 patients. Compared to a previous study published 10 years earlier, the bleeding complication rate was reduced to $10 \%$ vs. $20 \%$ [20].

Non-invasive monitoring of ICP using infrared spectroscopy, trans-cranial doppler and jugular venous oximetry has also been described in the literature. The use of invasive monitoring should be reserved for patients with the highest risk of cerebral oedema, i.e., those with grade IV encephalopathy or those with evidence of evolving intracranial hypertension [20]. Adequate sedation and analgesia is important in the management of hepatic encephalopathy as it minimizes intracranial pressure (ICP) rises associated with agitation and painful stimulation. Sedation can reduce the cerebral metabolic rate foroxygen $\left(\mathrm{CMRO}_{2}\right)$ and cerebral oxygen consumption [21] [22].

Circulatory dysfunction and hypotension occur frequently in patients with ALF. There is evidence of a high cardiac output, low systemic resistance state with alterations in hepatic and splanchnic blood flow in these patients [5]. Doppler ultrasonography of the hepatic blood vessels in 18 patients with acetaminophen-induced FH [23] revealed significant increases in the resistance to hepatic artery flow late after overdose, raising the possibility of a secondary ischaemic insult to the liver after the initial drug hepatotoxicity. Adrenocortical insufficiency may also contribute to hypotension.

Arterial hypotension that persists despite adequate fluid resuscitation requires the addition of vasopressors 
medication to maintain CPP. Norepinephrine is the preferred agent; however, more recently the vasopressin analogue terlipressin has been used in ALF with conflicting results [24] [25]. For the reasons mentioned, patients with ALF require invasive hemodynamic monitoring. These procedures are usually safe to perform, even in the presence of profound coagulopathy and haemorrhagic complications are rarely seen [26].

Patients with ALF develop significant coagulopathy due to diminished production of clotting factors by the damaged liver. Correcting the coagulopathy has historically involved the transfusion of fresh frozen plasma, platelets, cryoprecipitate, and packed red blood cells. However, the use of these products often does not correct the coagulopathy [27] [28].

Supplemental doses of vitamin $\mathrm{K}$ also does not improve the coagulopathy in acute liver failure [29]. The use of FFP should be discouraged unless there is active hemorrhage, or the patient is haemodynamically unstable [30]. If the correction of coagulopathy is necessary and adequate correction cannot be achieved with FFP, particularly in a volume overloaded patients, recombinant human factor VIIa should be considered. Recombinant factor VII (rFVIIa) helps to form as table clot by establishing complexes with exposed tissue factor, and it also enhances platelet activation [31] [32].

Patients with fulminant hepatitis are particularly susceptible to both bacterial and fungal infections. The milieu of inflammation and necrosis in ALF is presumed to predispose patients to infection due to complement deficiency, and/or impaired polymorphonuclear or Kupffer cellfunction. Bacteraemia has been reported in between $22 \%-80 \%$ of ALF patients and fungemia noted in 32\% [33]. Two observational studies from the UK and the US [34] [35] reported a high incidence of systemic inflammatory response syndrome and sepsis in FH. Patients with ALF should therefore be screened aggressively for evidence of infection. The use of prophylactic antibiotics remains controversial. However, they have been shown to significantly reduce the risk of sepsis, decrease the risk of progression to high-grade encephalopathy and increase the potential for successful transplantation; having said this, survival was not affected [35].

According to the AASLD guidelines, in the absence of active infection, antibiotic and antifungal therapy should be considered for all patients who show progression to high grade encephalopathy or those with evidence of significant systemic inflammation [10]. First-line antibiotic choice is dependent on unit-specific antimicrobial surveillance data and results from admission cultures.

Finally, renal dysfunction may occur in more than $50 \%$ of patients with ALF, and these patients often require continuous hemofiltration [20].

\subsection{Liver Transplant}

Fulminant hepatitis is one of the indications for orthotopic liver transplantation, and remains a well-established procedure for patients, without sufficient regeneration of hepatocytes, that is proven to improve survival. Before liver transplantation became a treatment option, survival rates were as low as $15 \%$. With liver transplantation, rates of between $60 \%$ to $80 \%$ have been reported in different series within the last decade [2] [36]. However, whole organ transplantation is invasive, expensive and increasingly limited by the unavailability of suitable donor organs.

In addition to whole-organ deceased donor liver transplantation, other types of transplantation have been attempted in this setting. Living donor liver transplantation (LDLT) accounted for approximately $2 \%$ of transplants for ALF between January 1, 1988 and March 31, 2010 (Based on Organ Procurement and Transplantation Network [OPTN] data as of May, 2011). The use of LDLT remains controversial and unique ethical issues exist [37]-[41]. The donor evaluation must be compressed which carries the risk of an incomplete evaluation and the possibility of donor coercion.

The team and the donor must consider the associated donor complications, including death, which occurs in 0.2\% of donors [42]-[44]. Nevertheless, right-lobe LDLT improves survival of patients with acute liver failure, and the 1-year survival following LDLT is approximately $75 \%$ [38]. The decision for transplantation depends on estimating the probability of spontaneous recovery and may be very difficult and requires weighing the advantages of an early transplantation against the disadvantages of an unnecessary transplantation with all consequences.

The principles underpinning the selection of patients with ALF are the accurate identification of those in need, as well as those who will benefit from liver transplantation.

The King's College Criteria (KCC) are probably the best validated tools currently available [45]; however, 
the predictive value of KCC has been questioned in the USA [14] because the encephalopathy grade and aetiology are the only predictors of outcome. Furthermore, the KCC has not been sufficiently evaluated in central Europe, where acetaminophen is not the major cause of FHF [46].

Using selection criteria for transplantation in patients with FH is wrong. In fact, it is illusory to think that a single set of criteria is relevant to FH of any cause. For this reason, a specific score according to the aetiology has been proposed: non-paracetamol-induced ALF in KCH criteria, blood arterial lactate [47], serum phosphate [48] [49], $\alpha$-fetoprotein [50] in paracetamol-induced ALF, prognostic factors for HAV infection-related FH [51], a prognostic scoring model for liver transplantation in patients with non-paracetamol-related ALF [52], prognostic factors of Amanita phalloides poisoning [53] [54].

In contrast, Novelli et al. [5] proposed prognostic criteria after treatment with the molecular adsorbent recirculating system (MARS), not depending onaetiology. In a multivariate logistic regression analysis of 45 patients diagnosed with FH, the authors showed six risk factors (the percentage reduction of lactate, IL-6 and ICP, systemic vascular resistance index values, GCS $<9$, and the number of MARS treatments) that could be considered predictive for transplant and outcome. The results highlighted that thirty-six patients survived: 21 were bridged to liver transplant and 15 continued the extracorporeal method until native liver recovery with a positive resolution of the clinical condition. Nine patients died before transplantation due to multi-organ failure.

It is well described in literature that the most important factor for predicting survival in $\mathrm{FH}$ is the degree of encephalopathy. For instance, spontaneous recovery is more likely with lower grades of encephalopathy [15]. It is between $65 \%$ to $70 \%$ in patients with grade I-II encephalopathy and less than $20 \%$ in patients with grade IV encephalopathy.

The one-year survival rates based on registry data were 74\% in Europe between 1988 and 2000 and 82\% in the US between1999 and 2008 [55]-[57]. Three large studies have attempted to define the characteristics associated with a poor outcome after liver transplantation for ALF [56] [58] [59]. None of the studies identified any specific characteristics of the severity of ALF pre-transplant as being predictive of outcome but three broad indicators were identified-renal dysfunction (creatinine $>2 \mathrm{mg} / \mathrm{dl}$ ), mechanical ventilation and inotrope dependence [57].

\subsection{Liver Support Devices}

Extracorporeal liver support systems are divided into biological, non-biological (also called artificial or cell-free techniques) and bio-artificial (hybrid techniques) devices. The potential usefulness of an extracorporeal liver support therapy could facilitate an improved environment for hepatic regeneration and clinical recovery. In anideal situation such an instrument would prevent the evolution to irreversible multi-organ failure and obviate the need for transplantation in many cases.

It is important to state that the vast majority of reports of the clinical application of liver support devices are as case reports or case series. Adverse effects of treatments include loss of platelets, increase in coagulation time, and electrolyte imbalances. Bleeding and disseminated intravascular coagulation can worsen hepatic function and increase encephalopathy and thus over shadow the detoxification effects of the treatments.

Artificial liver support technologies using albumin as a binding and scavenging molecule are mostly used. Albumin dialysis involves dialyzing blood against an albumin-containing solution across a highly permeable high-flux membrane. The blood-bound toxins are cleared by diffusion and taken up by the binding sites of the albumin dialysate. Two different albumin dialysis systems have been developed using this principle: MARS (Molecular Adsorbent Recirculation System) and SPAD (Single-Pass Albumin Dialysis). Prometheus (Fractionated Plasma Separation and Adsorption, or FPSA) differs from the others in that the patient's plasma is separated across amembrane and then is run over adsorptive columns. In particular, the MARS system is currently the most extensively used non-biological liver support system. The device was developed by Stange and Mitzner in 1993 and applied for the first time in humans in 1996.

Four large prospective randomized controlled trials (RCT) have evaluated the efficacy of MARS therapy [60]-[63]. Application of MARS was shown to be safe with only rare adverse events and resulted in an improvement of encephalopathy. However, no effect on survival was shown. A systematic review by Kjaergard et al. [64] and a Cochrane review (Liu, JP et al. Artificial and bioartificial support systems for liver failure. Cochrane Database of Systematic Reviews, Issue 1. Art. No.: CD003628) suggested that artificial support systems reduce mortality in acute-on-chronic liver failure compared with standard intensive care. However, artificial and 
bio-artificial support systems do not seem to affect mortality in patients with acute liver failure.

Stutchfield et al. [65] evaluated the role of contemporary extracorporeal liver support devices in patients with acute and acute-on-chronic liver failure through a meta-analysis of randomized controlled studies. They concluded that these systems seemed to improve survival in patients with acute liver failure.

In a recent study, Saliba et al. [66] conducted a randomized, controlled trial on 102 ALF patients that were divided in two groups: conventional treatment $(n=49)$ or MARS with conventional treatment $(n=53)$, stratified according to whether paracetamol caused ALF. Six-month survival was 75.5\% (95\% CI, 60.8\% to 86.2\%) with conventional treatment and $84.9 \%(\mathrm{CI}, 71.9 \%$ to $92.8 \%)$ with MARS (P $=0.28)$. This randomized trial of MARS in patients with ALF was unable to provide definitive efficacy or safety conclusions because many of the patients had been transplanted before administration of the intervention.

The conflicting results reported in literature are based on different applications of MARS therapy without a uniform consensus. The timing of application, the setting of blood and albumin circuit flows, albumin concentrations, membrane pressure and type of dialysis machine are fundamental in other to obtain the maximal detoxification.

\section{Summary and Future Steps}

Fulminant hepatitis is a complex clinical "syndrome" which requires early diagnosis and aggressive management.

Although orthotopic liver transplantation is the "gold standard" treatment for irreversible liver failure, the dramatic shortage of donor organs for transplantation has led to alternative strategies, such as the use of liver support, marginal organs, donation after cardiac death and living-donor liver transplantation, with considerable risk for the recipient (and in the case of living donor liver transplantation, for the healthy donor). Novel biomarkers, which predict outcome, are urgently needed so that resource utilization can be stratified appropriately.

Other targets of study should include systems analyses of cytokine studies, correlation with genomic analyses, development of prognostic scores, and a basic understanding of the inciting agents for liver injury. Much work has been done, and a number of novel promising approaches have emerged from preclinical and early clinical work. For instance, the use of recombinant human hepatocyte growth factor or HMGB-1 or bone marrow-derived stem cells orcardiotrophin-1 is considered potential interventions for ALF even if based on animal studies in some cases only.

\section{References}

[1] Schiodt, F.V., Atillasoy, E., Shakil, A.O., Schiff, E.R., Caldwell, C., Kowdley, K.V., Stribling, R., Crippin, J.S., Flamm, S., Somberg, K.A., et al. (1999) Etiology and Outcome for 295 Patients with Acute Liver Failure in the United States. Liver Transplantation and Surgery: Official Publication of the American Association for the Study of Liver Diseases and the International Liver Transplantation Society, 5, 29-34. http://dx.doi.org/10.1002/lt.500050102

[2] Ostapowicz, G., Fontana, R.J., Schiodt, F.V., Larson, A., Davern, T.J., Han, S.H., McCashland, T.M., Shakil, A.O., Hay, J.E., Hynan, L., et al. (2002) Results of a Prospective Study of Acute Liver Failure at 17 Tertiary Care Centers in the United States. Annals of Internal Medicine, 137, 947-954. http://dx.doi.org/10.7326/0003-4819-137-12-200212170-00007

[3] Szabo, G., Mandrekar, P. and Dolganiuc, A. (2007) Innate Immune Response and Hepatic Inflammation. Seminars in Liver Disease, 27, 339-350. http://dx.doi.org/10.1055/s-2007-991511

[4] O’Grady, J.G. (2005) Acute Liver Failure. Postgraduate Medical Journal, 81, 148-154. http://dx.doi.org/10.1136/pgmj.2004.026005

[5] Novelli, G., Rossi, M., Ferretti, G., Pugliese, F., Ruberto, F., Lai, Q., Novelli, S., Piemonte, V., Turchetti, L., Morabito, V., et al. (2009) Predictive Criteria for the Outcome of Patients with Acute Liver Failure Treated with the Albumin Dialysis Molecular Adsorbent Recirculating System. Therapeutic Apheresis and Dialysis: Official Peer-Reviewed Journal of the International Society for Apheresis, the Japanese Society for Apheresis, the Japanese Society for Dialysis Therapy, 13, 404-412.

[6] Trey, C. and Davidson, C.S. (1970) The Management of Fulminant Hepatic Failure. Progress in Liver Diseases, 3 , 282-298.

[7] O’Grady, J.G., Schalm, S.W. and Williams, R. (1993) Acute Liver Failure: Redefining the Syndromes. Lancet, 342, 273-275. http://dx.doi.org/10.1016/0140-6736(93)91736-6

[8] Bernuau, J. and Benhamou, J.P. (1993) Classifying Acute Liver Failure. Lancet, 342, 252-253. 
http://dx.doi.org/10.1016/0140-6736(93)91809-Z

[9] Acharya, S.K., Dasarathy, S. and Tandon, B.N. (1993) Should We Redefine Acute Liver Failure? Lancet, 342, 1421-1422. http://dx.doi.org/10.1016/0140-6736(93)92778-R

[10] Polson, J. and Lee, W.M. (2005) American Association for the Study of Liver D: AASLD Position Paper: The Management of Acute Liver Failure. Hepatology, 41, 1179-1197. http://dx.doi.org/10.1002/hep.20703

[11] Ichai, P. and Saliba, F. (2009) Fulminant and Subfulminant Hepatitis: Causes and Treatment. Presse Medicale, 38, 1290-1298.

[12] Farci, P., Alter, H.J., Shimoda, A., Govindarajan, S., Cheung, L.C., Melpolder, J.C., Sacher, R.A., Shih, J.W. and Purcell, R.H. (1996) Hepatitis C Virus-Associated Fulminant Hepatic Failure. The New England Journal of Medicine, 335, 631-634. http://dx.doi.org/10.1056/NEJM199608293350904

[13] Ichai, P. and Samuel, D. (2008) Etiology and Prognosis of Fulminant Hepatitis in Adults. Liver Transplantation: Official Publication of the American Association for the Study of Liver Diseases and the International Liver Transplantation Society, 14, S67-S79. http://dx.doi.org/10.1002/lt.21612

[14] Lee, W.M., Squires Jr., R.H., Nyberg, S.L., Doo, E. and Hoofnagle, J.H. (2008) Acute Liver Failure: Summary of a Workshop. Hepatology, 47, 1401-1415. http://dx.doi.org/10.1002/hep.22177

[15] O’Grady, J.G., Alexander, G.J., Hayllar, K.M. and Williams, R. (1989) Early Indicators of Prognosis in Fulminant Hepatic Failure. Gastroenterology, 97, 439-445.

[16] Brandsaeter, B., Hockerstedt, K., Friman, S., Ericzon, B.G., Kirkegaard, P., Isoniemi, H., Olausson, M., Broome, U., Schmidt, L., Foss, A. and Bjøro, K. (2002) Fulminant Hepatic Failure: Outcome after Listing for Highly Urgent Liver Transplantation-12 Years Experience in the Nordic Countries. Liver Transplantation: Official Publication of the American Association for the Study of Liver Diseases and the International Liver Transplantation Society, 8, 1055-1062.

[17] Auzinger, G. and Wendon, J. (2008) Intensive Care Management of Acute Liver Failure. Current Opinion in Critical Care, 14, 179-188. http://dx.doi.org/10.1097/MCC.0b013e3282f6a450

[18] Lidofsky, S.D., Bass, N.M., Prager, M.C., Washington, D.E., Read, A.E., Wright, T.L., Ascher, N.L., Roberts, J.P., Scharschmidt, B.F. and Lake, J.R. (1992) Intracranial Pressure Monitoring and Liver Transplantation for Fulminant Hepatic Failure. Hepatology, 16, 1-7. http://dx.doi.org/10.1002/hep.1840160102

[19] Davies, M.H., Mutimer, D., Lowes, J., Elias, E. and Neuberger, J. (1994) Recovery Despite Impaired Cerebral Perfusion in Fulminant Hepatic Failure. Lancet, 343, 1329-1330. http://dx.doi.org/10.1016/S0140-6736(94)92471-6

[20] Bernal, W. and Wendon, J. (2013) Acute Liver Failure. The New England Journal of Medicine, 369, $2525-2534$. http://dx.doi.org/10.1056/NEJMra1208937

[21] Karvellas, C.J., Pink, F., McPhail, M., Cross, T., Auzinger, G., Bernal, W., Sizer, E., Kutsogiannis, D.J., Eltringham, I. and Wendon, J.A. (2009) Predictors of Bacteraemia and Mortality in Patients with Acute Liver Failure. Intensive Care Medicine, 35, 1390-1396. http://dx.doi.org/10.1007/s00134-009-1472-x

[22] Trewby, P.N. and Williams, R. (1977) Pathophysiology of Hypotension in Patients with Fulminant Hepatic Failure. Gut, 18, 1021-1026. http://dx.doi.org/10.1136/gut.18.12.1021

[23] Deasy, N.P., Wendon, J., Meire, H.B. and Sidhu, P.S. (1999) The Value of Serial Doppler Ultrasound as a Predictor of Clinical Outcome and the Need for Transplantation in Fulminant and Severe Acute Liver Failure. The British Journal of Radiology, 72, 134-143.

[24] Eefsen, M., Dethloff, T., Frederiksen, H.J., Hauerberg, J., Hansen, B.A. and Larsen, F.S. (2007) Comparison of Terlipressin and Noradrenalin on Cerebral Perfusion, Intracranial Pressure and Cerebral Extracellular Concentrations of Lactate and Pyruvate in Patients with Acute Liver Failure in Need of Inotropic Support. Journal of Hepatology, 47, 381-386. http://dx.doi.org/10.1016/j.jhep.2007.04.015

[25] Shawcross, D.L., Davies, N.A., Mookerjee, R.P., Hayes, P.C., Williams, R., Lee, A. and Jalan, R. (2004) Worsening of Cerebral Hyperemia by the Administration of Terlipressin in Acute Liver Failure with Severe Encephalopathy. Hepatology, 39, 471-475. http://dx.doi.org/10.1002/hep.20044

[26] Fisher, N.C. and Mutimer, D.J. (1999) Central Venous Cannulation in Patients with Liver Disease and CoagulopathyA Prospective Audit. Intensive Care Medicine, 25, 481-485. http://dx.doi.org/10.1007/s001340050884

[27] Chuansumrit, A., Chantarojanasiri, T., Isarangkura, P., Teeraratkul, S., Hongeng, S. and Hathirat, P. (2000) Recombinant Activated Factor VII in Children with Acute Bleeding Resulting from Liver Failure and Disseminated Intravascular Coagulation. Blood Coagulation \& Fibrinolysis: An International Journal in Haemostasis and Thrombosis, 11, S101-S105.

[28] Cochran, J.B. and Losek, J.D. (2007) Acute Liver Failure in Children. Pediatric Emergency Care, 23, 129-135. http://dx.doi.org/10.1097/PEC.0b013e3180308f4b

[29] Mehta, R., Reilly, J.J. and Olson, R.E. (1991) Vitamin K Therapy in Severe Liver Disease. JPEN Journal of Parenteral 
and Enteral Nutrition, 15, 350-353. http://dx.doi.org/10.1177/0148607191015003350

[30] Rahman, T. and Hodgson, H. (2001) Clinical Management of Acute Hepatic Failure. Intensive Care Medicine, 27, 467476. http://dx.doi.org/10.1007/s001340100873

[31] Hoffman, R., Mahajana, A., Agmon, P., Baruch, Y. and Brenner, B. (2002) Successful Use of Recombinant Activated Factor VII (Novoseven) in Controlling Severe Intra-Abdominal Bleeding after Liver Needle Biopsy. Thrombosis and Haemostasis, 87, 346-347.

[32] Pugliese, F., Ruberto, F., Summonti, D., Perrella, S., Cappannoli, A., Tosi, A., D’Alio, A., Bruno, K., Martelli, S., Celli, P., et al. (2007) Activated Recombinant Factor VII in Orthotopic Liver Transplantation. Transplantation Proceedings, 39, 1883-1885. http://dx.doi.org/10.1016/j.transproceed.2007.05.062

[33] Chung, R.T., Stravitz, R.T., Fontana, R.J., Schiodt, F.V., Mehal, W.Z., Reddy, K.R. and Lee, W.M. (2012) Pathogenesis of Liver Injury in Acute Liver Failure. Gastroenterology, 143, e1-e7. http://dx.doi.org/10.1053/j.gastro.2012.07.011

[34] Rolando, N., Wade, J., Davalos, M., Wendon, J., Philpott-Howard, J. and Williams, R. (2000) The Systemic Inflammatory Response Syndrome in Acute Liver Failure. Hepatology, 32, 734-739. http://dx.doi.org/10.1053/jhep.2000.17687

[35] Vaquero, J., Polson, J., Chung, C., Helenowski, I., Schiodt, F.V., Reisch, J., Lee, W.M. and Blei, A.T. (2003) Infection and the Progression of Hepatic Encephalopathy in Acute Liver Failure. Gastroenterology, 125, 755-764. http://dx.doi.org/10.1016/S0016-5085(03)01051-5

[36] Gotthardt, D., Riediger, C., Weiss, K.H., Encke, J., Schemmer, P., Schmidt, J. and Sauer, P. (2007) Fulminant Hepatic Failure: Etiology and Indications for Liver Transplantation. Nephrology Dialysis Transplantation: Official Publication of the European Dialysis and Transplant Association-European Renal Association, 22, viii5-viii8.

[37] Berg, C.L., Gillespie, B.W., Merion, R.M., Brown Jr., R.S., Abecassis, M.M., Trotter, J.F., Fisher, R.A., Freise, C.E., Ghobrial, R.M., Shaked, A., Fair, J.H. and Everhart, J.E. (2007) Improvement in Survival Associated with Adult-toAdult Living Donor Liver Transplantation. Gastroenterology, 133, 1806-1813. http://dx.doi.org/10.1053/j.gastro.2007.09.004

[38] Campsen, J., Blei, A.T., Emond, J.C., Everhart, J.E., Freise, C.E., Lok, A.S., Saab, S., Wisniewski, K.A., Trotter, J.F. and Adult-to-Adult Living Donor Liver Transplantation Cohort Study Group (2008) Outcomes of Living Donor Liver Transplantation for Acute Liver Failure: The Adult-to-Adult Living Donor Liver Transplantation Cohort Study. Liver Transplantation: Official Publication of the American Association for the Study of Liver Diseases and the International Liver Transplantation Society, 14, 1273-1280.

[39] Liu, C.L., Fan, S.T., Lo, C.M., Yong, B.H., Fung, A.S. and Wong, J. (2002) Right-Lobe Live Donor Liver Transplantation Improves Survival of Patients with Acute Liver Failure. The British Journal of Surgery, 89, 317-322. http://dx.doi.org/10.1046/j.0007-1323.2001.02035.x

[40] Nishizaki, T., Hiroshige, S., Ikegami, T., Uchiyama, H., Hashimoto, K., Soejima, Y. and Shimada, M. (2002) LivingDonor Liver Transplantation for Fulminant Hepatic Failure in Adult Patients with a Left-Lobe Graft. Surgery, 131, S182-S189. http://dx.doi.org/10.1067/msy.2002.119574

[41] Uemoto, S., Inomata, Y., Sakurai, T., Egawa, H., Fujita, S., Kiuchi, T., Hayashi, M., Yasutomi, M., Yamabe, H. and Tanaka, K. (2000) Living Donor Liver Transplantation for Fulminant Hepatic Failure. Transplantation, 70, 152-157.

[42] Brown Jr., R.S., Russo, M.W., Lai, M., Shiffman, M.L., Richardson, M.C., Everhart, J.E. and Hoofnagle, J.H. (2003) A Survey of Liver Transplantation from Living Adult Donors in the United States. The New England Journal of Medicine, 348, 818-825. http://dx.doi.org/10.1056/NEJMsa021345

[43] Ghobrial, R.M., Freise, C.E., Trotter, J.F., Tong, L., Ojo, A.O., Fair, J.H., Fisher, R.A., Emond, J.C., Koffron, A.J., Pruett, T.L. and Olthoff, K.M. (2008) Donor Morbidity after Living Donation for Liver Transplantation. Gastroenterology, 135, 468-476. http://dx.doi.org/10.1053/j.gastro.2008.04.018

[44] Yasutomi, M., Uemoto, S., Inomata, Y. and Tanaka, K. (2000) Liver Failure Following Living Donor Liver Transplantation for Fulminant Hepatic Failure. Transplantation Proceedings, 32, 2133. http://dx.doi.org/10.1016/S0041-1345(00)01602-X

[45] Renner, E.L. (2007) How to Decide When to List a Patient with Acute Liver Failure for Liver Transplantation? Clichy or King's College Criteria, or Something Else? Journal of Hepatology, 46, 554-557. http://dx.doi.org/10.1016/j.jhep.2007.01.009

[46] Escorsell, A., Mas, A. and de la Mata, M. (2007) Spanish Group for the Study of Acute Liver F: Acute Liver Failure in Spain: Analysis of 267 Cases. Liver Transplantation: Official Publication of the American Association for the Study of Liver Diseases and the International Liver Transplantation Society, 13, 1389-1395.

[47] Bernal, W., Donaldson, N., Wyncoll, D. and Wendon, J. (2002) Blood Lactate as an Early Predictor of Outcome in Paracetamol-Induced Acute Liver Failure: A Cohort Study. Lancet, 359, 558-563. http://dx.doi.org/10.1016/S0140-6736(02)07743-7 
[48] Baquerizo, A., Anselmo, D., Shackleton, C., Chen, T.W., Cao, C., Weaver, M., Gornbein, J., Geevarghese, S., Nissen, N., Farmer, D., Demetriou, A. and Busuttil, R.W. (2003) Phosphorus Ans an Early Predictive Factor in Patients with Acute Liver Failure. Transplantation, 75, 2007-2014. http://dx.doi.org/10.1097/01.TP.0000063219.21313.32

[49] Chung, P.Y., Sitrin, M.D. and Te, H.S. (2003) Serum Phosphorus Levels Predict Clinical Outcome in Fulminant Hepatic Failure. Liver Transplantation: Official Publication of the American Association for the Study of Liver Diseases and the International Liver Transplantation Society, 9, 248-253.

[50] Schmidt, L.E. and Dalhoff, K. (2005) Alpha-Fetoprotein Is a Predictor of Outcome in Acetaminophen-Induced Liver Injury. Hepatology, 41, 26-31. http://dx.doi.org/10.1002/hep.20511

[51] Taylor, R.M., Davern, T., Munoz, S., Han, S.H., McGuire, B., Larson, A.M., Hynan, L., Lee, W.M., Fontana, R.J. and Group USALFS (2006) Fulminant Hepatitis A Virus Infection in the United States: Incidence, Prognosis, and Outcomes. Hepatology, 44, 1589-1597. http://dx.doi.org/10.1002/hep.21439

[52] Miyake, Y., Iwasaki, Y., Makino, Y., Kobashi, H., Takaguchi, K., Ando, M., Sakaguchi, K. and Shiratori, Y. (2007) Prognostic Factors for Fatal Outcomes Prior to Receiving Liver Transplantation in Patients with Non-Acetaminophen-Related Fulminant Hepatic Failure. Journal of Gastroenterology and Hepatology, 22, 855-861. http://dx.doi.org/10.1111/j.1440-1746.2007.04874.x

[53] Escudie, L., Francoz, C., Vinel, J.P., Moucari, R., Cournot, M., Paradis, V., Sauvanet, A., Belghiti, J., Valla, D., Bernuau, J. and Durand, F. (2007) Amanita phalloides Poisoning: Reassessment of Prognostic Factors and Indications for Emergency Liver Transplantation. Journal of Hepatology, 46, 466-473. http://dx.doi.org/10.1016/j.jhep.2006.10.013

[54] Ganzert, M., Felgenhauer, N. and Zilker, T. (2005) Indication of Liver Transplantation Following Amatoxin Intoxication. Journal of Hepatology, 42, 202-209. http://dx.doi.org/10.1016/j.jhep.2004.10.023

[55] Freeman Jr., R.B., Steffick, D.E., Guidinger, M.K., Farmer, D.G., Berg, C.L. and Merion, R.M. (2008) Liver and Intestine Transplantation in the United States, 1997-2006. American Journal of Transplantation: Official Journal of the American Society of Transplantation and the American Society of Transplant Surgeons, 8, 958-976.

[56] Germani, G., Theocharidou, E., Adam, R., Karam, V., Wendon, J., O’Grady, J., Burra, P., Senzolo, M., Mirza, D., Castaing, D., et al. (2012) Liver Transplantation for Acute Liver Failure in Europe: Outcomes over 20 Years from the ELTR Database. Journal of Hepatology, 57, 288-296. http://dx.doi.org/10.1016/j.jhep.2012.03.017

[57] O’Grady, J. (2013) Timing and Benefit of Liver Transplantation in Acute Liver Failure. Journal of Hepatology, 60, 663-670.

[58] Barshes, N.R., Lee, T.C., Balkrishnan, R., Karpen, S.J., Carter, B.A. and Goss, J.A. (2006) Risk Stratification of Adult Patients Undergoing Orthotopic Liver Transplantation for Fulminant Hepatic Failure. Transplantation, 81, 195-201. http://dx.doi.org/10.1097/01.tp.0000188149.90975.63

[59] Bernal, W., Cross, T.J., Auzinger, G., Sizer, E., Heneghan, M.A., Bowles, M., Muiesan, P., Rela, M., Heaton, N., Wendon, J. and O’Grady, J.G. (2009) Outcome after Wait-Listing for Emergency Liver Transplantation in Acute Liver Failure: A Single Centre Experience. Journal of Hepatology, 50, 306-313. http://dx.doi.org/10.1016/j.jhep.2008.09.012

[60] Hassanein, T.I., Tofteng, F., Brown Jr., R.S., McGuire, B., Lynch, P., Mehta, R., Larsen, F.S., Gornbein, J., Stange, J. and Blei, A.T. (2007) Randomized Controlled Study of Extracorporeal Albumin Dialysis for Hepatic Encephalopathy in Advanced Cirrhosis. Hepatology, 46, 1853-1862. http://dx.doi.org/10.1002/hep.21930

[61] Heemann, U., Treichel, U., Loock, J., Philipp, T., Gerken, G., Malago, M., Klammt, S., Loehr, M., Liebe, S., Mitzner, S., Schmidt, R. and Stange, J. (2002) Albumin Dialysis in Cirrhosis with Superimposed Acute Liver Injury: A Prospective, Controlled Study. Hepatology, 36, 949-958.

[62] Mitzner, S.R., Stange, J., Klammt, S., Risler, T., Erley, C.M., Bader, B.D., Berger, E.D., Lauchart, W., Peszynski, P., Freytag, J., et al. (2000) Improvement of Hepatorenal Syndrome with Extracorporeal Albumin Dialysis MARS: Results of a Prospective, Randomized, Controlled Clinical Trial. Liver Transplantation: Official Publication of the American Association for the Study of Liver Diseases and the International Liver Transplantation Society, 6, 277-286.

[63] Sen, S., Davies, N.A., Mookerjee, R.P., Cheshire, L.M., Hodges, S.J., Williams, R. and Jalan, R. (2004) Pathophysiological Effects of Albumin Dialysis in Acute-on-Chronic Liver Failure: A Randomized Controlled Study. Liver Transplantation: Official Publication of the American Association for the Study of Liver Diseases and the International Liver Transplantation Society, 10, 1109-1119.

[64] Kjaergard, L.L., Liu, J., Als-Nielsen, B. and Gluud, C. (2003) Artificial and Bioartificial Support Systems for Acute and Acute-on-Chronic Liver Failure: A Systematic Review. JAMA: The Journal of the American Medical Association, 289, 217-222. http://dx.doi.org/10.1001/jama.289.2.217

[65] Stutchfield, B.M., Simpson, K. and Wigmore, S.J. (2011) Systematic Review and Meta-Analysis of Survival Following Extracorporeal Liver Support. The British Journal of Surgery, 98, 623-631. http://dx.doi.org/10.1002/bjs.7418

[66] Saliba, F., Camus, C., Durand, F., Mathurin, P., Letierce, A., Delafosse, B., Barange, K., Perrigault, P.F., Belnard, M., Ichai, P. and Samuel, D. (2013) Albumin Dialysis with a Noncell Artificial Liver Support Device in Patients with 
Acute Liver Failure: A Randomized, Controlled Trial. Annals of Internal Medicine, 159, 522-531. http://dx.doi.org/10.7326/0003-4819-159-8-201310150-00005

\section{Key Points}

1. Fulminant hepatitis is a "complex syndrome”, and its management requires a multi-disciplinary approach.

2. The aetiology of fulminant hepatitis varies in different regions and has changed over time.

3. Identifying the cause of fulminant hepatitis is an important step in the management of acute liver failure as it allows for early-targeted therapy.

4. Early disease recognition and better intensive care management has led to an improvement in survival over the last few years.

5. Prognostic models, which predict outcome in fulminant hepatitis, are needed to better distinguish patients who will improve spontaneously from those requiring transplantation. 